\title{
LETTER
}

\section{Ventilation inhomogeneity is one criterion among many in multidimensional PEEP titration}

\author{
Zhanqi Zhao',2*, Daniel Steinmann², Inéz Frerichs³, Josef Guttmann² and Knut Möller' \\ See related commentary by Costa and Amato, http://ccforum.com/content/14/2/134
}

We appreciate the commentary from Dr Costa and Dr Amato [1] on our recent study [2], in which we proposed that ventilation inhomogeneity should be regarded as an additional prospective index along with blood gases, lung mechanics and hemodynamics in a multifactorial method to optimize positive end-expiratory pressure (PEEP) at the bedside.

We agree with Costa and Amato that some ventilation heterogeneity may be good [1]. Especially in patients with normal lungs, inhomogeneity of lung perfusion and ventilation along the gravity axis match each other - a match that is essential to optimize gas exchange. Little attention was paid, however, to isogravitational inhomogeneity of pulmonary perfusion and ventilation. When isogravitational inhomogeneity is included in the estimation, the influence of gravity is no longer dominant $[3,4]$. Minimizing the ventilation inhomogeneity during PEEP titration is not intended to eliminate inhomogeneity at all (which is impossible by PEEP alone), but rather to find a balance between overdistension and atelectasis. Physiological heterogeneity (good heterogeneity) may be preserved at the selected PEEP level.

The global inhomogeneity index [2] can be independently combined with any region-of-interest-definition method, if appropriate. Given that no perfect method exists currently for identification of collapsed lung areas by electrical impedance tomography, our approach [5] guarantees to include as much of the collapsed lung regions as is detectable in the analysis of ventilation inhomogeneity and provides satisfactory results, as shown in a preliminary study by comparison with computed tomography.

The titration of PEEP actually requires a multidimensional approach. A single ideal PEEP level, satisfying all clinical objectives and situations, may even not exist. A weighted combination of lung mechanics, blood gas analysis and imaging techniques to titrate PEEP therefore seems appealing and promising.

\section{Abbreviations}

PEEP, positive end-expiratory pressure.

\section{Competing interests}

The authors declare that they have no competing interests.

\section{Author details}

'Department of Biomedical Engineering, Furtwangen University, JakobKienzle-Strasse 17, D-78054 Villingen-Schwenningen, Germany. ${ }^{2}$ Department of Anesthesiology and Critical Care Medicine, Section for Experimental Anesthesiology, University Medical Center, Hugstetter Strasse 49, D-79095 Freiburg, Germany. ${ }^{3}$ Department of Anesthesiology and Intensive Care Medicine, University Medical Center of Schleswig-Holstein, Campus Kiel, Arnold-Heller-Strasse 3, D-24105 Kiel, Germany.

Published: 17 June 2010

\section{References}

1. Costa EL, Amato MB: Can heterogeneity in ventilation be good? Crit Care 2010, 14:134.

2. Zhao Z, Steinmann D, Frerichs I, Guttmann J, Moller K: PEEP titration guided by ventilation homogeneity: a feasibility study using electrical impedance tomography. Crit Care 2010, 14:R8.

3. Glenny R: Counterpoint: Gravity is not the major factor determining the distribution of blood flow in the healthy human lung. J App/ Physio/ 2008, 104:1533-1535; discussion 1535-1536.

4. Zhao Z, Kiefer N, Kulcsar M, Lang S, Möller K: Ventilation inhomogeneity in upright and supine position assessed by electrical impedance tomography. In XII Mediterranean Conference on Medical and Biological Engineering and Computing. 27-30 May, 2010; Chalkidiki, Greece. Edited by Bamidis PD, Konstantindis ST, Bliznakova K and Pallikarakis N. Springer; 2010:84. ISBN 978-960-99365-0-7.

5. Zhao Z, Steinmann D, Müller-Zivkovic D, Martin J, Frerichs I, Guttmann J, Möller K: A lung area estimation method for analysis of ventilation inhomogeneity based on electrical impedance tomography. J Xray Sci Technol 2010, 18:171-182.

\section{doi:10.1186/cc9037}

Cite this article as: Zhao Z, et al.: Ventilation inhomogeneity is one criterion among many in multidimensional PEEP titration. Critical Care 2010, 14:424.

\footnotetext{
${ }^{*}$ Correspondence: zhanqi.zhao@hs-furtwangen.de

'Department of Biomedical Engineering, Furtwangen University, Jakob-Kienzle-

Strasse 17, D-78054 Villingen-Schwenningen, Germany

Full list of author information is available at the end of the article
} 